\title{
Steve Murphy, Rimbaud et la Commune. Microlectures et perspectives
}

\section{Mario Richter}

\section{Q OpenEdition}

1 Journals

\section{Edizione digitale}

URL: http://journals.openedition.org/studifrancesi/6375

DOI: 10.4000/studifrancesi.6375

ISSN: 2421-5856

\section{Editore}

Rosenberg \& Sellier

\section{Edizione cartacea}

Data di pubblicazione: 1 novembre 2010

Paginazione: 575

ISSN: 0039-2944

\section{Notizia bibliografica digitale}

Mario Richter, «Steve Murphy, Rimbaud et la Commune. Microlectures et perspectives», Studi Francesi [Online], 162 (LIV | III) | 2010, online dal 30 novembre 2015, consultato il 11 janvier 2021. URL: http:// journals.openedition.org/studifrancesi/6375 ; DOI: https://doi.org/10.4000/studifrancesi.6375

Questo documento è stato generato automaticamente il 11 janvier 2021.

\section{(c) (i) (9)}

Studi Francesi è distribuita con Licenza Creative Commons Attribuzione - Non commerciale - Non opere derivate 4.0 Internazionale. 


\title{
Steve Murphy, Rimbaud et la Commune. Microlectures et perspectives
}

\author{
Mario Richter
}

\section{NOTIZIA}

STEVE MURPHY, Rimbaud et la Commune. Microlectures et perspectives, Paris, Éditions

Classiques Garnier, 2010, pp. 916.

1 Questo libro imponente si presenta come il pendant di quello che lo stesso autore pubblicò una ventina d'anni fa, Rimbaud et la ménagerie impériale (1991). Il fatto ormai assodato, soprattutto grazie agli studi attenti dello stesso Steve Murphy e di Yves Reboul, è che, all'opposto di una convinzione ancora abbastanza diffusa secondo cui Rimbaud avrebbe abbandonato l'impegno politico dopo la repressione della Commune, il poeta fu un attivo sostenitore del movimento rivoluzionario senza poi dissociarsene.

2 Pur riconoscendo con la sua abituale probità che alcuni problemi restano tuttora irrisolti, Murphy ci mette ora a disposizione uno strumento storico-critico-esegetico di primissima qualità, fondato su una esposizione sorretta da una ricca documentazione dell'intera questione riguardante il rapporto di Rimbaud con l'evento rivoluzionario di gran lunga più rilevante e più conturbante del suo tempo. I suoi lettori, pur essendo in parte già al corrente delle principali linee-guida dell'argomento, trovano adesso molte eccellenti analisi inedite e comunque notevolmente arricchite quando non interamente ripensate. Si possono in tal modo leggere con grande profitto i commenti ai testi che maggiormente rivelano la loro diretta appartenenza alla Commune come Le Cour supplicié, Chant de guerre Parisien, L'Orgie parisienne ou Paris se repeuple, L'Homme juste e Les mains de Jeanne-Marie nonché quelli, meno esplicitamente collegati all'evento, come Le Bateau ivre, Bonne pensée du matin e Les Corbeaux, fino a quelli che prefigurano la disfatta e la sfida come Les Poètes de sept ans, Les Pauvres à l'Église e Les Premières Communions. Di non minore interesse sono le perlustrazioni di Murphy nel mondo del primissimo Rimbaud, nella rilettura critica delle lettere scritte fra aprile e maggio 1871 e nella 
rivalutazione dei rapporti del poeta con Verlaine. Le sue esegesi non sono il risultato, come spesso avviene, di una lettura che si avvale delle conoscenze e dei gusti attuali del critico, ma traggono ragione e forza da un ricupero particolarmente ampio e attento della temperie politica degli anni in cui Rimbaud scriveva. Ecco con quali convincenti termini l'A. espone questa sua necessità di storico: «... les textes rimbaldiens exigent, pour que l'on puisse les lire un peu comme les aurait lus un lecteur qui en était le contemporain, la prise en compte de connotations et d'implications qui ne nous sont pas aujourd'hui spontanément accessibles» (p. 10). In tal modo murphy percorre un itinerario critico inverso a quello di quanti hanno feticizzato il lirismo visionario di Rimbaud senza voler sufficientemente tener conto, come bene precisa l'A., che si tratta di una poesia legata alla poesia epica e soprattutto a quella satirica e polemica. Su questa via Murphy si dichiara convinto che l'impegno morale del poeta inteso a raggiungere la "liberté libre" non può essere separato dalle trasformazioni politiche della società. «L'auteur d'Après le Déluge, de Ville et de Génie» è appunto la conclusione «ne fournit pas un manifeste communiste ou un programme révolutionnaire, mais il continue à s'interroger sur la nature de la société et de l'Histoire et en recherchant toujours cette 'liberté libre' que la France des années 1870 faisait tout pour étouffer» (p. 864).

3 Il libro risulta infine corredato da significative e poco note illustrazioni, nonché da una eccellente, aggiornatissima «Bibliographie rimbaldo-verlainienne». 